\title{
Lower extremity venous thrombosis in patients younger than 50 years of age
}

This article was published in the following Dove Press journal:

Vascular Health and Risk Management

12 March 2012

Number of times this article has been viewed

\section{Raghid Kreidy' \\ Pascale Salameh ${ }^{2}$ \\ Mirna Waked ${ }^{3}$}

'Department of Vascular Surgery, Saint George Hospital, University Medical Center, University of Balamand, ${ }^{2}$ Laboratory of Clinical and Epidemiological Research, Faculty of Pharmacy, Lebanese University, ${ }^{3}$ Department of Pulmonary Medicine, Saint George Hospital, University Medical Center, University of Balamand, Beirut, Lebanon
Correspondence: Raghid Kreidy Department of Vascular Surgery, Saint George Hospital, University Medical Center, Youssef Sursock Street, PO Box 166378, Achrafieh,

Beirut, I 100 2807, Lebanon

Tel +96I 3275007

Fax+96I I 565530

Email docrkdy@inco.com.lb
Aim: Lower extremity deep venous thrombosis in the young adult is uncommon and has not been well studied in the literature. The aim of this study is to define risk factors for deep venous thrombosis among patients younger than 50 years of age, to compare them with a control group, and to suggest recommendations for the management and treatment of venous thrombosis in this particular group of patients.

Methods: From January 2003 to January 2011, 66 consecutive Lebanese patients (29 males and 37 females) younger than 50 years, diagnosed in an academic tertiary-care center with lower extremity deep venous thrombosis by color flow duplex scan, were retrospectively reviewed. Their age varied between 21 and 50 years (mean 38.7 years). The control group included 217 patients ( 86 males and 131 females) older than 50 years (range: 50-96 years; mean 72.9 years).

Results: The most commonly reported risk factors in the younger age group were inherited thrombophilia (46.9\% compared with $13.8 \%$ in the control group; $P<0.001$ ), pregnancy (18.2\% compared with $0.5 \% ; P<0.001)$, treatment with estrogen drugs $(13.6 \%$ compared with $2.3 \% ; P=0.001)$, and family history of venous thromboembolism $(9.1 \%$ compared with $3.8 \% ; P=0.084)$.

Conclusion: Inherited thrombophilia is the most commonly observed risk factor among patients younger than 50 years, with a prevalence of three times more than the control group. Young adults should be screened for thrombophilia even in the presence of transient acquired risk factors. Pregnancy and treatment with estrogen drugs essentially when associated with inherited thrombophilia represent a frequent cause of venous thrombosis among young female patients. Inferior vena cava abnormalities should be excluded in young patients with spontaneous proximal venous thrombosis especially when recurrent venous thrombosis or resistance to anticoagulation are observed.

Keywords: venous thrombosis, lower extremities, young patient, risk factors, genetics

\section{Introduction}

Lower extremity deep venous thrombosis (DVT) is predominantly a disease of older age. ${ }^{1}$ The incidence of DVT increases exponentially with age for both idiopathic and secondary DVT rising nearly 90 -fold between 15 and 80 years of age with a relative risk of 1.9 for each 10-year increase in age. ${ }^{2,3}$ It is uncommon in young adults and very rare before the age of 20 years. ${ }^{4}$ It is extremely rare in children occurring in only $0.22 \%$ of hospitalized pediatric patients. ${ }^{5}$

The appropriate management of venous thrombosis requires a thorough knowledge of the underlying epidemiology and associated risk factors. Pathophysiology and risk factors for venous thrombosis among young adults vary considerably compared with 
those reported for the general population. Very few papers assessing these risk factors in young adults have been published in the literature.

The aim of this study is to define risk factors for DVT among Lebanese patients younger than 50 years, to compare them with a control group, and to propose recommendations for diagnosis, management, and treatment of venous thrombosis in this particular group of patients.

\section{Materials and methods}

From January 2003 to January 2010, 66 consecutive Lebanese patients (29 males and 37 females) younger than 50 years of age, diagnosed in an academic tertiary-care center with lower extremity DVT using color flow duplex scan (Prosound Alpha 7 ALOKA, Zug, Switzerland), were retrospectively reviewed. Age varied from 21 to 50 years (mean 38.7 years). Fourteen patients $(21.2 \%)$ were aged 20 -30 years of age, 22 patients $(33.3 \%)$ were $30-40$ years, and 38 patients $(45.5 \%)$ were $40-50$ years. Control group included 217 patients (86 males and 131 females) older than 50 years. The mean age of the patients in the control group was 72.9 years (range 50-96 years).

Thrombophilia was screened among patients with specific conditions highly suggestive of hypercoagulation states according to the guidelines proposed by the European Genetics Foundation, the Cardiovascular Educational and Research Trust, the International Union of Angiology and the Mediterranean League on Thromboembolism. ${ }^{6}$ These conditions were young age ( $\leq 50$ years), spontaneous, extended and recurrent DVT, family history of venous thromboembolism (VTE), oral contraceptives and estroprogestative treatment, long-haul air travel, pregnancy, inferior vena cava (IVC) congenital abnormalities, and resistance to anticoagulation.

A clinical research form was filled out with every patient, by a retrospective evaluation of clinical presentation and risk factors for venous thrombosis; data were entered and analyzed by SPSS Statistics (IBM Corporation, Somers, NY) software, version 13.0. A chi-square test was used to correlate between dichotomous variables, and a Fisher exact test was used in case of calculated values that were lower than five. Clinical presentation and risk factors for venous thrombosis were determined in the group of patients under the age of 50 and in the control group.

\section{Results}

The great majority of patients younger than 50 years of age with confirmed venous thrombosis were outpatients (72.7\% compared with $56.2 \%$ in the control group; $P=0.0017$ ).

The side of lower extremity venous thrombosis did not statistically vary between the younger adult group and the control group. However, venous thrombosis was more commonly located at the ilio-femoral and femoro-popliteal level in the younger age group compared with the control group (62\% comparing to $49.3 \% ; P=0.001$ ) (Table 1 ). Three patients younger than 50 years $(4.5 \%)$ and twelve patients older than 50 years $(5.5 \%)$ developed pulmonary embolism.

In these series, thrombophilia was the most commonly reported risk factor for venous thrombosis among patients younger than 50 years with a threefold increased rate compared with the control group (46.7\% compared with $13.8 \%$; $P<0.001)$. Ninety four percent of the patients in the younger age group and all the patients in the control group tested for thrombophilia were positive. Prandoni demonstrated that the

Table I Sociodemographic and deep venous thrombosis (DVT) characteristics of comparison groups

\begin{tabular}{|c|c|c|c|c|}
\hline Characteristic & $\begin{array}{l}\text { Young patients } \\
N=66\end{array}$ & $\begin{array}{l}\text { Older patients } \\
N=217\end{array}$ & $P$-value & $\begin{array}{l}\text { Total } \\
N=283\end{array}$ \\
\hline Gender & & & 0.533 & \\
\hline Males & 29 (43.9\%) & 86 (39.6\%) & & II 5 (40.6\%) \\
\hline Females & 37 (56.1\%) & $|3|$ (60.4\%) & & I 68 (59.4\%) \\
\hline Hospitalization & & & 0.017 & \\
\hline Yes & I8 (27.3\%) & 95 (43.8\%) & & II 3 (39.9\%) \\
\hline No & 48 (72.7\%) & 122 (56.2\%) & & 170 (60.1\%) \\
\hline DVT side & & & 0.248 & \\
\hline Right side & $21(37.8 \%)$ & $86(39.6 \%)$ & & $107(37.8 \%)$ \\
\hline Left side & 39 (59.1\%) & $103(47.5 \%)$ & & $142(50.2 \%)$ \\
\hline Bilateral & $6(9.1 \%)$ & 28 (I2.9\%) & & 34 (12.0\%) \\
\hline DVT level & & & 0.001 & \\
\hline Calf & 25 (37.9\%) & 110 (50.7\%) & & I 35 (47.7\%) \\
\hline Femoro-popliteal & 14 (21.1\%) & 67 (30.9\%) & & 81 (28.6\%) \\
\hline Ilio-femoral & 27 (40.9\%) & 40 (I8.4\%) & & $67(23.7 \%)$ \\
\hline
\end{tabular}


Table 2 Risk factors for deep venous thrombosis in young age group and control group

\begin{tabular}{|c|c|c|c|c|}
\hline Risk factors & $\begin{array}{l}\text { Young patients } \\
N=66\end{array}$ & $\begin{array}{l}\text { Older patients } \\
N=217\end{array}$ & $P$-value & $\begin{array}{l}\text { Total } \\
N=\mathbf{2 8 3}\end{array}$ \\
\hline Thrombophilia & $46.9 \%$ & $13.8 \%$ & $<0.001$ & $6 \mathrm{I}(2 \mathrm{I} .5 \%)$ \\
\hline Thrombophilia testing* & $33(94.3 \%)$ & $30(100 \%)$ & 0.495 & $63(96.9 \%)$ \\
\hline Pregnancy/postpartum & $12(18.2 \%)$ & I (0.5\%) & $<0.001$ & $13(4.6 \%)$ \\
\hline Obesity & $10(15.2 \%)$ & $55(25.3 \%)$ & 0.085 & $65(23.0 \%)$ \\
\hline Family history of VTE & $6(9.1 \%)$ & 7 (3.2\%) & 0.084 & $13(4.6 \%)$ \\
\hline Varicose veins & $8(12.1 \%)$ & $24(11.1 \%)$ & 0.812 & 32 (11.3\%) \\
\hline Malignancy & $6(9.1 \%)$ & $29(13.4 \%)$ & 0.356 & 35 (12.4\%) \\
\hline Personal history of VTE & $10(15.2 \%)$ & $44(20.3 \%)$ & 0.353 & $54(19.1 \%)$ \\
\hline Long-haul air travel & $3(4.5 \%)$ & $3(1.4 \%)$ & 0.142 & $6(2.1 \%)$ \\
\hline IVC congenital abnormalities & $2(0.9 \%)$ & $\mathrm{I}(0.5 \%)$ & 0.552 & $4(1.4 \%)$ \\
\hline Chronic obstructive pulmonary disease & $0 \%$ & $3(1.4 \%)$ & 1.000 & $3(1.1 \%)$ \\
\hline Alzheimer disease & $0 \%$ & $2(0.9 \%)$ & 1.000 & $2(0.7 \%)$ \\
\hline Chronic renal failure/dialysis & $0 \%$ & $6(2.8 \%)$ & 0.342 & $6(2.1 \%)$ \\
\hline Inflammatory bowel disease & $2(3.0 \%)$ & $\mathrm{I}(0.5 \%)$ & 0.137 & $3(1.1 \%)$ \\
\hline Hormonal/estrogen treatment & $9(13.6 \%)$ & $5(2.3 \%)$ & 0.001 & 14 (4.9\%) \\
\hline Hip fracture & $2(3.0 \%)$ & $15(6.9 \%)$ & 0.245 & $17(6.0 \%)$ \\
\hline Heart failure & $0 \%$ & $24(11.1 \%)$ & 0.005 & $24(8.5 \%)$ \\
\hline Post-operation/surgery & $12(18.2 \%)$ & $39(18.0 \%)$ & 0.969 & $51(18.0 \%)$ \\
\hline Immobilization & $5(7.6 \%)$ & 43 (19.8\%) & 0.020 & $48(17.0 \%)$ \\
\hline Trauma & $\mathrm{I}(1.5 \%)$ & $6(2.8 \%)$ & 0.567 & $7(2.5 \%)$ \\
\hline Mean number of risk factors (SD) & $1.83(1.03 \%)$ & $1.56(1.01 \%)$ & 0.058 & $1.63(1.02)$ \\
\hline$\geq 3$ risk factors & $13(19.7 \%)$ & $39(18.0 \%)$ & 0.751 & $52(18.5 \%)$ \\
\hline
\end{tabular}

Notes: *Thrombophilia was tested in 35 young and 30 older individuals. Bold indicates results that are statistically significant or very suggestive.

Abbreviations: IVC, inferior vena cava; SD, standard deviation; VTE, venous thromboembolism.

frequency of thrombophilia outside the setting of surgery, trauma, or cancer is approximately $25 \% .^{7}$ This frequency was very high in the reported younger adult group (63.4\%) and low in the control group (19.8\%). Pregnancy and postpartum were very important risk factors in the younger age group (18.2\% compared with $0.5 \% ; P<0.001)$.

Treatment with estrogen drugs was more frequently reported among patients younger than 50 years of age compared with older patients (13.6\% compared with $2.3 \%$; $P=0.001)$. On the other hand, heart failure $(P=0.05)$ and immobilization $(P=0.02)$ were more commonly observed among older patients in the control group (Table 2).

In the reported study, patients younger than 50 years old exhibit higher genetic mutation rate for factors $V R$ 506 Q-Leiden (68.6\% compared with 43.3\%; $P=0.041$ ) and for the homozygote and heterozygote forms of methylenetetrahydrofolate reductase (MTHFR) C $677 \mathrm{~T}$ (11.4\% compared with $3.3 \% ; P=0.063$ ). The other prothrombotic genetic mutations did not statistically vary in the two groups (Table 3).

Table 3 Prothrombotic genetic mutations in young age group and control group (when tested)

\begin{tabular}{|c|c|c|c|c|}
\hline Thrombophilia & $\begin{array}{l}\text { Young patients } \\
N=35\end{array}$ & $\begin{array}{l}\text { Older patients } \\
\mathbf{N}=30\end{array}$ & P-value & $\begin{array}{l}\text { Total } \\
\mathbf{N}=65\end{array}$ \\
\hline Factor V R 506 Q-leiden any & $24(68.6 \%)$ & 13 (43.3\%) & 0.041 & 37 (56.9\%) \\
\hline Homozygote & $3(8.6 \%)$ & $2(6.7 \%)$ & 0.136 & $5(7.7 \%)$ \\
\hline Heterozygote & $21(60 \%)$ & I I (36.7\%) & & $32(49.2 \%)$ \\
\hline MTHFR C 677 T any & 14 (40\%) & $18(60 \%)$ & 0.108 & $32(49.2 \%)$ \\
\hline Homozygote & 4 ( I I.4\%) & I (3.3\%) & 0.063 & 5 (7.7\%) \\
\hline Heterozygote & $10(28.6 \%)$ & $17(56.7 \%)$ & & $27(41.5 \%)$ \\
\hline MTHFR A 1298 C heterozygote & $4(\mathrm{I} 1.4 \%)$ & $6(20.0 \%)$ & 0.493 & $10(15.4 \%)$ \\
\hline Prothrombin G 20210 A heterozygote & $3(8.6 \%)$ & I $(3.3 \%)$ & 0.618 & $4(6.2 \%)$ \\
\hline Factor V H I 299 R heterozygote & I (2.9\%) & I (3.3\%) & 1.000 & $2(3.1 \%)$ \\
\hline Protein C deficiency & I $(2.9 \%)$ & $0 \%$ & 1.000 & $\mathrm{I}(\mathrm{I} .5 \%)$ \\
\hline Protein S deficiency & $0 \%$ & I (3.3\%) & 0.462 & I (I.5\%) \\
\hline Increased homocysteine level & $7(20 \%)$ & $9(30 \%)$ & 0.351 & $16(24.6 \%)$ \\
\hline Antiphospholipid syndrome & I (2.9\%) & $0 \%$ & 0.351 & I (I.5\%) \\
\hline
\end{tabular}

Note: Bold indicates results that are statistically significant or very suggestive. 


\section{Discussion}

The development of clinically manifest venous thrombosis most often occurs with the convergence of multiple genetic and acquired risk factors. Young adults usually manifest severe forms of VTE. Determination of acquired and genetic risk factors for venous thrombosis among young adults is essential for appropriate management and treatment of this disease in this particular group of patients.

Thrombophilia, a hyper-coagulation state is common in the adult patient and occurs in approximately $50 \%$ to $70 \%$ of idiopathic VTE, ${ }^{8,9}$ in $39.5 \%$ to $53.5 \%$ of pregnant women, ${ }^{10,11}$ and in $72 \%$ of individuals with travel-related VTE. ${ }^{12}$ The relative risks of developing a first episode of VTE in patients with documented acquired and genetic thrombophilia are increased from two- to elevenfold. ${ }^{13}$ In some series, inherited thrombophilia has been detected in $34 \%$ of young adults with venous thrombosis. ${ }^{14,15}$ In others, thrombophilia has been reported in $18.8 \%$ to $34 \%$ of young female patients with venous thrombosis and in $49 \%$ of young female patients with venous thrombosis and using oral contraceptives. ${ }^{16,17}$ Inherited thrombophilia has been recognized as a risk factor for pediatric VTE, but its significance has not been thoroughly investigated. ${ }^{18}$

In a very recent study, thrombophilia has been observed in 7\% of hospitalized children with VTE..$^{5}$ In these series, inherited thrombophilia was the most common risk factor for lower extremity DVT in the younger age group occurring in $46.9 \%$ of the patients. The high rate of inherited thrombophilia observed in the younger age group is related to the high prevalence of factor V-Leiden, MTHFR C 677 T and A $1298 C$ among Lebanese patients. ${ }^{19-21}$ Factor V-Leiden and MTHFR C $677 T$ mutation was more frequently detected among younger patients compared with older patients. The mutant allele was highly expressed among young adults with DVT and high-risk conditions for hypercoagulation state. The finding that patients with thrombophilia can harbor more than one prothrombotic genetic defect has further increased the relevance of the congenital thrombophilic states. Patients younger than 50 years of age should be screened for thrombophilia even in the presence of transient risk factor. We suggest testing for less frequently examined factor $V H 1299 R$ and MTHFR A $1298 C$ in countries with very high prevalence of these mutations, and in young adults with extended VTE resistant to anti-coagulation, when not justified by the most common mutations. The incidence of venous thrombosis increases among pregnant women and among women using oral contraceptives and increases significantly when those women are carriers for prothrombotic genetic defects.
Prothrombin G $20210 \mathrm{~A}$ and factor V-Leiden mutation increases the risks of venous thrombosis 3.4- to 34-fold in pregnant women ${ }^{10,11,22-24}$ and 2.9- to 35-fold in women treated with oral contraceptives and estrogen. ${ }^{25,26}$ In the reported series, $31.8 \%$ of younger patients and $56.7 \%$ of younger female patients were pregnant or treated with oral contraceptives or estrogen drugs, emphasizing the role of hormonal impregnation in the pathogeneses of venous thrombosis. Ninety percent of these patients were carriers for genetic abnormalities, which further increased the risks of venous thrombosis. Because of this high risk for venous thrombosis, young females with a family history of VTE should be tested for prothrombotic genetic abnormalities prior to treatment initiation with oral contraceptives or estrogen. Nine percent of patients younger than 50 years observed in this study reported a family history of VTE. All younger patients with such a family history were tested for thrombophilia and were positive. This finding suggests screening for thrombophilia in all patients with a strong family history for VTE essentially when the thrombosis is spontaneous or when it occurs at a young age. When venous thrombosis develops spontaneously at a young age, it is commonly related to the presence of prothrombotic polymorphism, sometimes associated with congenital inferior vena cava abnormalities. ${ }^{27}$ Lambert et al identified these congenital anomalies in $5 \%$ of patients younger than 30 years presenting for unprovoked DVT. ${ }^{25}$ The great majority of the patients were males and venous thrombosis occurred essentially after major physical activity. ${ }^{28}$ IVC congenital malformations have been reported in $16.2 \%$ of young patients with iliac vein thrombosis. ${ }^{29}$ When these malformations are associated with inherited genetic defects leading to thrombophilia, the risks of venous thrombosis are increased several times. ${ }^{30-33}$ The three reported patients with IVC anomalies (two left-sided and one agenesis) in this study were young males, complaining of iliac venous thrombosis and were carriers for prothrombotic genetic mutations. Although uncommon, congenital inferior vena cava abnormalities should be excluded in young patients with spontaneous proximal DVT involving the iliac veins, essentially when resistance to anticoagulants, or recurrent venous thrombosis, are observed. ${ }^{34}{ }^{40}$ When proximal venous thrombosis is located on the left side in young patients, May-Thurner syndrome should be suspected. Venous thrombosis risks increase when patients diagnosed with this syndrome are carriers for prothrombotic genetic defects. ${ }^{41,42}$ Air travel is associated with a threefold higher risk for VTE with an 18\% higher risk for each 2-hour increase in travel duration. ${ }^{43}$ In long-haul air flights, the quantitative risk of lower limbs venous thrombosis 
is $1.6 \%$ per flight with low risk subjects and $5 \%$ per flight for high risk subjects. ${ }^{44}$ The three young adults observed in these series with venous thrombosis occurring after long-haul air travel were females, carriers for genetic polymorphism and using oral contraceptives. One of these young adults had a family history of VTE and underwent recent surgery. Beside thrombophilic disorders, the risks of venous thrombosis increase significantly in young adults when additive known risk factors such as obesity, recent surgery, history of VTE, and oral contraceptive treatment are reported..$^{45}$

Maly et al demonstrated that the prevalence of occult cancer among patients under the age of 50 with VTE is low $(1.8 \%) .{ }^{46}$ Inherited thrombophilia is more often found in the young adult, but risk of occult malignancy exists as well. Although uncommon in young adults, malignancy should be considered when venous thrombosis is idiopathic, resistant to anti-coagulation, when clinical and biological findings are suggestive of cancer and when thrombophilia testing does not indicate a significant prothrombotic risk for the development of venous thrombosis. Following these rules, the authors observed a relatively high prevalence of malignancy among patients younger than 50 years of age with venous thrombosis $(9.1 \%)$.

Inflammatory bowel disease is a generally accepted risk factor for VTE among the young patient. ${ }^{47}$ The mechanism underlying this association remains unclear. VTE may be observed during both active disease or periods of remission. It has been more frequently reported in patients with extensive disease, colonic involvement, and with other associated extra-intestinal manifestations. ${ }^{48}$ Surgery and especially colorectal surgery carries an increased risk for venous thrombosis in patients with inflammatory bowel disease. ${ }^{49}$ Three young adults with venous thrombosis reported in this study have developed Crohn's disease. One of them was 28 years old and the two others were 44 years old. A recent study demonstrated that the risks of VTE are increased twofold in patients with inflammatory bowel disease..$^{50}$ Relative risks were particularly high among young patients and the risk incidence increases with age. ${ }^{50}$ In hospitalized children, inflammatory bowel disease has been reported to be one of the most common causes of VTE. ${ }^{51}$

Duration of the treatment of venous thrombosis in the young adult depends on the nature and extent of the thrombosis, the underlying risk factors, the presence of a previous VTE, the presence of congenital venous abnormalities, the presence and the severity of prothrombotic genetic mutation. ${ }^{52}$ Long-term treatment may be required to avoid recurrent venous thrombosis in young adults with idiopathic venous thrombosis, with continuous risk factors, with multiple episodes of venous thrombosis, and with severe inherited thrombophilia associated or not with congenital inferior vena cava and iliac abnormalities.

\section{Conclusion}

Inherited thrombophilia is the most commonly observed risk factor for venous thrombosis among patients younger than 50 years, with an increased prevalence of at least threefold compared with the control group. It should be screened for in patients under the age of 50 even in the presence of a transient risk factor. Young adults usually present with severe forms of venous thrombosis. They should be assessed for acquired and also genetic factors, which would then suggest extending the duration of anticoagulant therapy in high risk patients, reducing the incidence of post-thrombotic syndrome and venous thromboembolic recurrence.

Pregnancy and treatment with oral contraceptives or estrogen drugs, especially when associated with inherited thrombophilia, represent a frequent cause of DVT among young female patients. Screening for thrombophilia among young females with strong family history of VTE before starting estrogen therapy is warranted. Congenital abnormalities of the inferior vena cava and of the iliac veins should be excluded in young patients with spontaneous proximal DVT, involving the iliac veins, essentially when resistance to anticoagulant therapy or recurrent venous thrombosis is observed.

\section{Disclosure}

The authors report no conflicts of interest in this work.

\section{References}

1. Stein PD, Hull RD, Kayali F, Ghali WA, Alshab AK, Olson RE. Venous thromboembolism according to age; impact of an aging population. Arch Intern Med. 2004;164(20):2260-2266.

2. Naess IA, Christiansen SC, Romundstad P, et al. Incidence and mortality of venous thrombosis:a population-based study. J Thromb Haemost. 2007;5(4):692-699.

3. Montagnana M, Favaloro EJ, Franchini M, Guidi GC, Lipi G. The role of ethnicity, age and gender in venous thromboembolism. J Thromb Thrombolysis. 2010;29(4):489-496.

4. Kearon C. Epidemiology of venous thromboembolism. Semin Vasc Med. 2001;1(1):7-26

5. Wright JM, Watts RG. Venous thromboembolism in pediatric patients: epidemiologic data from a pediatric tertiary care center in Alabama. J Ped Hematol Oncol. 2011;33(4):261-264.

6. Nicolaides AN, Breddin HK, Carpenter P, et al. Thrombophilia and venous thromboembolism. Interrnational Consensus Statement. Guidelines according to scientific evidence. Int Angiol. 2005;24(1):1-26.

7. Prandoni P. Cancer and thromboembolic disease: how important is the risk of thrombosis? Cancer Treat Rev. 2002;28(3):133-136.

8. Cushman M. Inherited risk factors for venous thrombosis. Hematology. 2005;1:452-457. 
9. Salomon O, Steinberg DM, Zivelin A, et al. Single and combined prothrombotic factors in patients with idiopathic venous thromboembolism: prevalence and risk assessment. Arterioscl Thromb Vasc Biol. 1999;19(3):511-518.

10. Martinelli I, De Stefano V, Taioli E, Paciaroni K, Rossi E, Mannucci PM. Inherited thrombophilia and first venous thromboembolism during pregnancy and puerperium. Thromb Haemost. 2002;87(5):791-795.

11. De Stefano V, Rossi E, Leone G. Inherited thrombophilia, pregnancy and oral contraceptive use:clinical implications. Semin Vasc Med. 2003;3(1):47-60.

12. Parsi KA, Mcgrath MA, Lord RS. Traveller's venous thromboembolism. Cardiovasc Surg. 2001;9(2):157-158.

13. Meissner M, Wakefield T, Ascher E, et al. Acute venous disease: venous thrombosis and venous trauma. J Vasc Surg. 2007:46(Suppl): 25S-53S.

14. Ghosh K, Shetty S, Madkaikar M. Venous thromboembolism in young patients from Western India: a study. Clin Appl Thromb Hemost. 2001;7(2);158-165.

15. Binder B, Lackner HK, Salmhofer W, Hofmann-Wellenhof R. Risk factors for deep vein thrombosis in women aged 18 to 50: a retrospective analysis. Dermatol Surg. 2009;35(3):451-456.

16. Cozza S, Mercier G, Schved JF, Biron-Andréani C. Thrombophilia and transient risk factors for venous thromboembolism in women with distal deep vein thrombosis. Pathophysiol Haemost Thromb. 2008;36(5):282-284.

17. Pulicek P, Maly J, Pecka M, Barenek M, Cermakova E, Maly R. Venous thromboembolism in young females while on oral contraceptives: high frequency of inherited thrombophilia and analysis of thrombotic events in 400 Czech females. Clin Appl Thromb Hemost. 2009;15(5):567-573.

18. Spentzouris G, Scriven RJ, Lee TK, Labropoulos N. A review of pediatric venous thromboembolism in relation to adults. J Vasc Surg. 2011;22. [Epub ahead of print.]

19. Irani-Hakime N, Tamim H, Kreidy R, Almawi WY. Prevalence of factor V R 506 Q - Leiden among apparently healthy Lebanese patients. Am J Hemat. 2000;65(1):45-49.

20. Sabbagh AS, Mahfoud Z, Taher A, Zaatari G, Daher R, Mahfouz RA. High prevalence of gene A 1298 C polymorphism in Lebanon. Genet Test. 2008;12(1):75-80.

21. Almawi W, Finan RR, Tamim H, Daccache JL, Irani-Hakime N. Differences in the frequency of the C $677 \mathrm{~T}$ mutation in the methylenetetrahydrofolate reductase (MTHFR) gene among the Lebanese patients. Am J Hemat. 2004;76(1):85-87.

22. Pomp ER, Lensenlink AM, Rosendaal FR, Doggen CJ. Pregnancy, the postpartum period and postthrombotic defects: risk of venous thrombosis in the MEGA study. J Thromb Haemost. 2008;6(4): 632-637.

23. Normittag R, Pabinger I. Thrombophilia and pregnancy complications. Hamostaseologie. 2006;26(1):59-62.

24. Wu O, Robertson L, Twaddle S, et al. Screening for thrombophilia in high risk situations: systemic review and cost-effectiveness analysis. Thrombosis: Risk and Economic Assessment of Thrombophilia Screening (TREATS) study. Health Technol Assess. 2006;10(11):1-110.

25. Legnani C, Cosmi B, Valdre L, et al. Venous thromboembolism, oral contraceptives and high thrombin levels. J Thromb Haemost. 2003:1(1):112-117.

26. Rosendaal FR, Vessey M, Rumley A, et al. Hormonal replacement therapy, prothrombotic mutations and the risk of venous thrombosis. Br J Haematol. 2002;116(4):851-854.

27. Garcia-Fuster MJ, Forner MJ, Flor-Lorente B, Soler J, Campos S. Inferior vena cava malformations and deep vein thrombosis. Rev Esp Cardiol. 2006;59(2):171-175.

28. Lambert M, Marboeuf P, Midulla M. Inferior vena cava agenesis and deep venous thrombosis: 10 patients and review of the literature. Vasc Med. 2010;15(6):451-459.
29. Gil RJ, Perez AM, Arias JB, Pascual FB, Romero ES. Agenesis of the inferior vena cava associated with lower extremities and pelvic venous thrombosis. J Vasc Surg. 2006;44(5):1114-1116.

30. Sirlak M, Cakici M, Inan MB, et al. Coexistence of left-sided inferior vena cava, deep vein thrombosis of the upper and lower extremities and prothrombotic polymorphisms in a young patient: a case report. Blood Coagul Fibrinolysis. 2008;19(5):443-445.

31. Bianchi M, Giannini D, Balbarini A, Castiglioni MG. Congenital hypoplasia of the inferior vena cava and inherited thrombophilia: rare associated risk factors for idiopathic deep vein thrombosis. A case report. J Cardiovasc Med.(Hagerstown). 2008;9(1):101-104.

32. Fass G, Nasroolah D, Cavenaile JC. Deep vein thrombosis caused by congenital malformation of the inferior vena cava and heterozygous factor V Leiden presenting as venous claudication. Clin Appl Thromb Hemost. 2009;15(5):591-595.

33. Rose SS, Ali Y, Kumar A, Bekos TJ, Saidi P. Deep venous thrombosis caused by inferior vena cava atresia and hereditary thrombophilia. Am J Med Sc. 2009;337(1):67-70.

34. Lane DA. Congenital hypoplasia of the inferior vena cava: an underappreciated cause of deep vein thrombosis among young adults. Mil Med. 2005;170(9):739-742.

35. Parma M, Belotti D, Marinoni S, Pogliani EM. Congenital absence of the inferior vena cava and genetic coagulation abnormalities: a rare associated risk factor for recurrent idiopathic deep vein thrombosis. Clin Appl Thromb Hemost. 2003;9(4):347-348.

36. Sarlon G, Bartoli MA, Muller C, et al. Congenital anomalies of inferior vena cava in young patients with iliac deep venous thrombosis. Ann Vasc Surg. 2011;25(2):265-268.

37. Patel VK, Warner B, Ceccherini A, Mearns B. Agenesis inferior vena cava and anomalous venous drainage system. An unusual cause of bilateral deep venous thrombosis in a young adult. Acute Med. 2011;10(1):29-31.

38. Guanella R, Glauser F, Bounameaux H, Mazzolai L. Inferior vena cava agenesis: association with bilateral lower-limb deep vein thrombosis in young males. Thromb Haemost. 2009;102(4):795-798.

39. Kondo Y, Koizumi J, Nishibe M, Muto A, Dardik A, Nishibe T. Deep venous thrombosis caused by congenital absence of the inferior vena cava: report of a case. Surg Today. 2009;239(3):231-234.

40. Nseir W, Mahamid M, Abu-Rahmeh Z, Markel A. Recurrent deep venous thrombosis in a patient with agenesis of inferior vena cava. Int J Gen Med. 2011;4:457-459.

41. Kecskeméthy Z, Holy J. May-Thurner syndrome. Orv-Hetil. 2011;152(4): 139-141.

42. De BastY, Dahin L. May-Thurner syndrome will be completed? Thromb Res. 2009;123(3):498-502.

43. Chandra D, Parisini E, Mozaffarian D. Meta-analysis: travel and risk for venous thromboembolism. Ann Intern Med. 2009;151(3): 180-190.

44. Aryal KL, Al Khaffaf H. Venous thromboembolic complications following air travel. What's the quantitative risk? A literature review. Eur J Vasc Endovasc Surg. 2006;31(2):187-189.

45. Schobersberger W, Schobersberger B, Partsch H. Travel-related thromboembolism: mechanisms and avoidance. Expert Rev Cardiovasc Ther. 2009;7(12):1559-1567.

46. Maly R, Vodickova L. The occurrence of occult malignancy in patients less than fifty years of age with venous thromboembolism: which diagnostic screening methods to use? Vniter LeK. 2004;50(10): 751-755.

47. Shin do H, Lee KH, Kim CH, et al. A case of inferior vena cava thrombosis and acute pancreatitis in a patient with ulcerative colitis. Korean Gastroenterol. 2010;56(4):255-259.

48. Guerra Montero LJ, Ingver A, Casanas A, Soca S, Iade B. Clinical characteristics of patients with inflammatory bowel disease and clinical thromboembolic events. Acta Gastroenterol Latiniam. 2010;40(2);1354-1141. 
49. McLeods RS, Geerts WH, Sniderman KW, et al. Canadian Colorectal Surgery DVT Prophylaxis Trial investigators. Spontaneous heparin versus low-molecular-weight heparin as thromboprophylaxis in patients undergoing colorectal surgery: results of the Canadian colorectal DVT prophylaxis trial:a randomized double-blind trial. Ann Surg. 2001;233(3):438-444.

50. Kappelman MD, Horwath-Pulo E, Sandler RS, et al. Thrombophilic risk among Danish children and adults with inflammatory bowel diseases:a population-based nationwide study. Gut. 2011;60(7):937-943.
51. Vu LT, Nobuhara KK, Lee H, Farmer DL. Determination of risk factors for deep venous thrombosis in hospitalized children. J Pediatr Surg. 2008;43(6):1095-1099.

52. Kreidy R, Irani-Hakime N. Is thrombophilia a major risk factor for deep vein thrombosis of the lower extremities among Lebanese patients? Vasc Health Risk Manag. 2009;5:627-633.

\section{Publish your work in this journal}

Vascular Health and Risk Management is an international, peerreviewed journal of therapeutics and risk management, focusing on concise rapid reporting of clinical studies on the processes involved in the maintenance of vascular health; the monitoring, prevention and treatment of vascular disease and its sequelae; and the involvement of metabolic disorders, particularly diabetes. This journal is indexed on PubMed Central and MedLine. The manuscript management system is completely online and includes a very quick and fair peer-review system, which is all easy to use. Visit http://www.dovepress.com/ testimonials.php to read real quotes from published authors.

Submit your manuscript here: http://www.dovepress.com/vascular-health-and-risk-management-journal 